\title{
Protective effect of a sesamin derivative, 3-bis (3-methoxybenzyl) butane-1, 4-diol on ischemic and hypoxic neuronal injury
}

\author{
Chien-Wei Hou ${ }^{1 \dagger}$, Yi-Ling Chen ${ }^{1 \dagger}$, Shih-Hsien Chuang ${ }^{2}$, Jen-Shu Wang ${ }^{3}$ and Kee-Ching Jeng ${ }^{4 *}$
}

\begin{abstract}
Background: Stroke is one of the leading causes of neuronal death. Sesamin is known for neuroprotection by its antioxidant and anti-inflammatory properties but it lacks blood-brain barrier (BBB) activity. A panel of sesamin derivatives was screened and 3-bis (3-methoxybenzyl) butane-1,4-diol (BBD) was selected for high BBB activity and tested for its neuroprotective effect.

Methods: The focal cerebral ischemia of Sprague-Dawley rats and hypoxia models of murine BV-2 microglia or PC12 cells under oxygen/glucose deprivation were used for in vivo and in vitro test, respectively. Lipid peroxidation and superoxide dismutase (SOD) activity from the ischemic brain were tested and reactive oxygen species (ROS), cytokine production, prostaglandin $\left(\mathrm{PGE}_{2}\right)$ and related signaling pathways from hypoxic cells were examined by ELISA or Western blot assay, respectively.

Results: BBD showed a protective effect when given 90 min after the focal cerebral ischemia. It also reduced lipid peroxidation and preserved SOD activity from the ischemic brain. The mechanism of BBD was further confirmed by attenuating ROS, cytokine production, and $\mathrm{PGE}_{2}$ release from hypoxic BV-2 or PC12 cells. BBD significantly reduced hypoxia-induced c-Jun N-terminal kinases (JNK) and modulated AKT-1 and caspase-3 (survival and apoptotic pathways) in BV-2 cells, and inhibited hypoxia-induced JNK and cyclooxygenase-2 activation in PC12 cells.
\end{abstract}

Conclusions: The neuroprotective effect of BBD on ischemia/hypoxia models was involved with antioxidant and anti-inflammatory effects. The result would help the development of new CNS drug for protection of ischemia/ hypoxia injury.

Keywords: Cerebral ischemia, Hypoxia, Neuroprotection, Sesamin derivative, Membrane permeability

\section{Background}

Stroke is the most common disease in the elderly population. Ischemic stroke is commonly caused by thrombosis that results in acute cerebrovascular disease and the lack of glucose and oxygen would damage the neuronal cells. In Taiwan, cerebrovascular disease is one of the leading causes of death in recent years (Department of Health, Taiwan). Brain ischemia/hypoxia is characterized by an increase reactive oxygen species (ROS) generation and cytokine-mediated inflammatory reactions [1].

\footnotetext{
* Correspondence: kcjeng@gmail.com

${ }^{\dagger}$ Equal contributors

${ }^{4}$ Department of Medical Research, Tungs' Taichung MetroHarbor Hospital, 699 Taiwan Boulevard, Sec.8, Taichung 43503, Taiwan

Full list of author information is available at the end of the article
}

Studies have shown that ischemia/reperfusion of brain can cause cell damage by increasing inflammation from oxidative stress $[2,3]$. Previously we reported that sesamin protected cerebral ischemia and neuronal cell injuries under stress $[4,5]$. However, sesamin might not penetrate the $\mathrm{BBB}$ easily because it has to be pretreated for its neuroprotective effect to ischemia/hypoxia-induced injuries [4-6]. A good neuroprotective agent should be able to pass the blood-brain barrier (BBB) to reach the brain target site $[7,8]$.

Ischemia/hypoxia-induced ROS and cytokine can be scavenged by antioxidants [9]. Rat pheochromacytoma (PC12) cells and murine microglia BV-2 cells have been used as neuronal stress models $[4,5,10]$. Specifically, 
extracellular signal-regulated kinase (ERK), c-Jun Nterminal kinase (JNK) and p38 mitogen-activated protein kinase (MAPK) signaling pathways can be activated by ROS in PC12 cell and BV-2 cells [4,5]. Hypoxia-ischemia induces apoptosis in the brain is evident by release of cytochrome $\mathrm{c}$ and activation of caspase-3 [11]. Therefore in the present study, a compound, 3-bis (3-methoxybenzyl) butane-1,4-diol (BBD, Figure 1), with high membrane permeability was selected from a panel of newly synthesized sesamin derivatives to test its neuroprotective effect. The possible mechanism of BBD was investigated with ischemic brain and hypoxia models under oxygen and glucose deprivation (hypoxia) for ROS, cytokine, and $\mathrm{PGE}_{2}$ production. Hypoxia-induced MAPKs, apoptotic pathways, and COX-2 were also studied.

\section{Methods}

\section{Reagents}

Dimethylsulfoxide (DMSO), lucifer yellow, n-Dodecane, phosphate buffered saline (PBS), theophylline, and verapamil were obtained from Sigma-Aldrich Chemical (St. Louis, MO, USA). Porcine polar brain lipid (PBL) was purchased from Avanti Polar Lipids Inc. (Alabaster, AL, USA). $2^{\prime}, 7^{\prime}$-Dichlorodihydrofluorescein diacetate $\left(\mathrm{H}_{2} \mathrm{DCF}-\right.$ DA) was obtained from Molecular Probe (Eugene, Oregon, USA). Fetal bovine serum (FBS) was obtained from Gibco Invitrogen (Grand Island, NY, USA). Dulbecco's Modified Eagle's medium (DMEM) were purchased from GIBCO (Grand Island, NY, USA). Anti-phospho-p38, ERK, JNK, and $\beta$-actin antibodies were purchased from Abcam (Cambridge, UK). Anti-Akt1 (pSer ${ }^{473}$ ) antibody was purchased from Calbiochem (Darmstadt, Germany). 3-bis (3-methoxybenzyl) butane-1,4-diol (BBD) was kindly provided from Joben Bio-Medical Co. (Kaohsiung, Taiwan).

\section{Membrane permeability assay}

The blood-brain barrier limits drug access into the brain, due to tight junctions, membrane drug transporters, and unique lipid composition. Porcine whole-brain lipid is successfully used in passive permeability test for CNS drugs $[7,8]$.

The parallel artificial membrane permeation assay (PAMPA) was carried out in a sandwich-like 96-well PAMPA plate formed by a top filter plate containing acceptor wells and a bottom plate containing donor wells. Each composite well was divided into two chambers: $300 \mu \mathrm{l}$ of donor solution (test article or QC standards) at the bottom and $200 \mu \mathrm{l}$ of acceptor buffer (PBS buffer containing 5\% DMSO) at the top, separated by a polyvinylidene fluoride (PVDF, $0.45 \mu \mathrm{m}$ pore size) membrane, coated with $4 \mu \mathrm{l}$ of $20 \mathrm{mg} / \mathrm{ml}$ porcine polar brain lipid $(\mathrm{PBL})$ in $\mathrm{n}$-dodecane. Stock solutions of $2 \mathrm{mg} / \mathrm{mL}$ of a sesamin derivative (BBD), theophylline (low permeability standard), verapamil (high permeability standard), and lucifer yellow (used to assess lipid layer integrity in donor well) were prepared in DMSO and then diluted 20-fold in PBS buffer at $\mathrm{pH} 7.4$ to yield final concentrations of $100 \mu \mathrm{g} / \mathrm{ml}$ of each of working stock solutions. The final DMSO concentration in working stock solution is 5\%. Each compound was performed in triplicate. The test compound diffused from the donor well through the lipid membrane and into the acceptor well. The sandwich plate was placed with the plate lid and incubated at room temperature for approximately $18 \mathrm{~h}$. After reaching diffusion equilibration, the PAMPA sandwich plate was disassembled and the concentration of drug in the acceptor, the donor, and the reference wells was determined using a TECAN microplate reader (Durham, NC, USA). Effective permeability $\left(\mathrm{P}_{\mathrm{e}}\right)$ of the compounds was calculated using the Microsoft Office Excel 2010. The range for $\mathrm{P}_{\mathrm{e}}$ of a $\mathrm{BBB}+$ compound (high $\mathrm{BBB}$ permeation predicted): $\mathrm{P}_{\mathrm{e}}\left(10^{-6} \mathrm{~cm} \mathrm{~s}^{-1}\right)>4.0$; BBB- compound (low BBB permeation predicted): $\mathrm{P}_{\mathrm{e}}\left(10^{-6} \mathrm{~cm} \mathrm{~s}^{-1}\right)<2.0$; and $\mathrm{BBB}+/-$ compound (BBB permeation uncertain): $\mathrm{P}_{\mathrm{e}}\left(10^{-6} \mathrm{~cm} \mathrm{~s}^{-1}\right)$ from 4.0 to 2.0 [7].

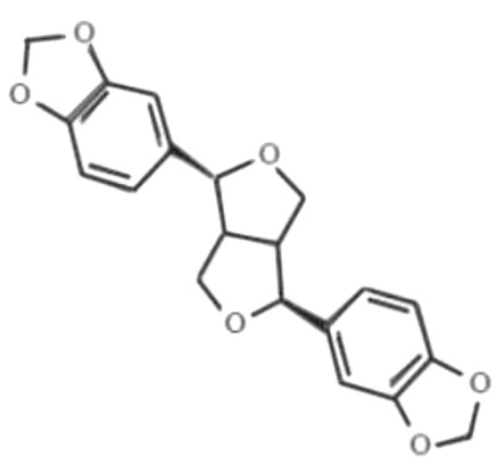

Sesamin

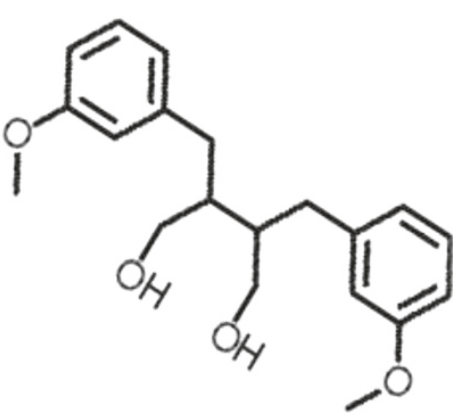

BBD

Figure 1 The chemical structure of sesamin and BBD. 


\section{Animal study}

Twenty-four male Sprague-Dawley (SD) rats (200 250 gm) were purchased from National Animal Center, Taipei, Taiwan and randomly divided into the control (normal saline), and BBD groups. The experiment was approved by Institutional Animal Care and Use Committee, Taichung Veterans General Hospital (IACUC LA-97490). Rats were injected intraperitoneally (i.p.) with BBD $(10 \mathrm{mg} / \mathrm{kg})$ 90 min after MACO experiment. Each SD rat was anesthetized with chlorohydrate $(400 \mathrm{mg} / \mathrm{kg}$ ) i.p. and its body temperature was maintained at $37^{\circ} \mathrm{C}$ with a heating pad (CMA/150). A midline neck incision was made and the right carotid artery was exposed and separated from the vago-sympathetic trunk. The right carotid artery was loosely encircled with a 4-O suture for later occlusion. The SD rat's head was placed in a stereotaxic frame (David Kopf, CA, USA) with the nose bar positioned $4.0 \mathrm{~mm}$ below the horizontal line. Following a midline incision, the skull was partially removed to expose the right middle cerebral artery. The middle cerebral artery was loosely encircled with an 8-O suture for later occlusion. A focal cerebral ischemia was induced by occlusion of the right common carotid artery and the right cerebral artery (MCAO) for $60 \mathrm{~min}$, followed by reperfusion. A laser probe $(0.8 \mathrm{~mm}$ in diameter $)$ of a Laser Doppler Blood Flow monitor (MBF 3D, Moor Instruments, Axminster, UK) was positioned onto the cortex with its tip close to the middle cerebral artery. Cerebral blood flow dropped to less than $5 \%$ of basal after the occlusion of the MCAO. Cerebral blood flow reached its minimal levels within 5 min after the start of the occlusion and was confirmed to remain at this level throughout the monitoring period to ensure the validity of the stroke model. Twenty-four hours after cerebral ischemia, each SD rat was anesthetized and perfused transcardially with isotonic heparinized saline and 2,3,5-triphenyltetrazolium chloride (TTC). The brain was then removed and sliced into five 2-mm-thick coronal sections for TTC staining.

\section{Cell culture}

Murine BV-2 microglial cell line was maintained in DMEM supplemented with $10 \%$ (v/v) FBS, $100 \mathrm{U} / \mathrm{ml}$ penicillin and $100 \mu \mathrm{g} / \mathrm{ml}$ streptomycin $(\mathrm{P} / \mathrm{S})$ in a humidified incubator under $5 \% \mathrm{CO}_{2}$ at $37^{\circ} \mathrm{C}$. Rat pheochromacytoma PC12 cell line was maintained in DMEM supplemented with $10 \%$ FBS, $5 \%$ horse serum, $\mathrm{P} / \mathrm{S}$ at $37^{\circ} \mathrm{C}$ under $5 \% \mathrm{CO}_{2}$. Confluent cultures were passaged by trypsinization. In all experiments, the cells were treated with BBD immediately before hypoxia. BBD was dissolved in DMSO. The final concentration of DMSO added to cells never exceeded $0.1 \%(\mathrm{v} / \mathrm{v})$.

\section{Hypoxia}

On the day of experiment, culture media were replaced with glucose-free DMEM, then, gassed with $85 \% \mathrm{~N}_{2}$,
$10 \% \mathrm{H}_{2}$, and $5 \% \mathrm{CO}_{2}$ for various time periods in the absence or presence of various doses of BBD.

\section{MTT assay}

Cell viability was measured using blue formazan that was metabolized from colorless 3-(4,5-dimethyl-thiazol-2-yl)2,5-diphenyl tetrazolium bromide (MTT) by mitochondrial dehydrogenases, which are active only in live cells. PC12 or BV2 cells were preincubated in 24-well plates at a density of $5 \times 10^{5}$ cells per well for $24 \mathrm{~h}$. Cells incubated with various concentrations of BBD were under hypoxia for $30 \mathrm{~min}$, and incubated in $0.5 \mathrm{mg} / \mathrm{ml} \mathrm{MTT}$ at $37^{\circ} \mathrm{C}$. One hour later, $200 \mu \mathrm{l}$ of solubilization solution were added to each well and absorption values read at $540 \mathrm{~nm}$ on microtiter plate reader (spectraMAX 340, Molecular Devices, Sunnyvale, CA, USA). Data were expressed as the mean percent of viable cells vs. control.

\section{LDH assay}

Cytotoxicity was determined by measuring the release of LDH. PC12 or BV-2 cells treated with various concentrations of BBD were stressed with hypoxia for one hour and the supernatant was then assayed for LDH activity. An absorbance was read at 490/630 nm using a spectraMAX 340 microtiter plate reader. Data were expressed as the mean percent of viable cells vs. the control.

\section{Generation of reactive oxygen species}

Intracellular accumulation of ROS was determined using $\mathrm{H}_{2}$ DCF-DA, which is a nonfluorescent compound that accumulates in cells following deacetylation. $\mathrm{H}_{2} \mathrm{DCF}$ then reacts with ROS to form fluorescent dichlorofluorescein (DCF). PC12 cells were plated in 96-well plates and grown for $24 \mathrm{~h}$ before addition of DMEM plus $10 \mu \mathrm{M}$ $\mathrm{H}_{2}$ DCF-DA, incubated for $60 \mathrm{~min}$ at $37^{\circ} \mathrm{C}$, and treated with various concentrations of $\mathrm{BBD}$ for hypoxia $30 \mathrm{~min}$. Cells were then washed twice at room temperature with Hank's balanced salt solution (HBSS without phenol red). Cellular fluorescence was monitored on a Fluoroskan Ascent fluorometer (Labsystems Oy, Helsinki, Finland) using an excitation wavelength of $485 \mathrm{~nm}$ and emission wavelength of $538 \mathrm{~nm}$.

\section{Measurement of cytokine assay}

Cytokines (IL-1 $\beta$, IL-6) and PGE $_{2}$ were measured using ELISA kits (R\&D, Minneapolis, MN, USA). The absorbance at $450 \mathrm{~nm}$ was determined using a microplate reader (spectraMAX 340).

\section{Western blot}

Samples containing $25 \mu \mathrm{g}$ of protein were separated on $12.5 \%(\mathrm{w} / \mathrm{v})$ sodium dodecyl sulfate-polyacrylamide gels, and transferred to immobilon polyvinylidenedifluoride membranes (Millipore, Bedford, USA). The membranes 
Table 1 The PAMPA-BBB permeation of BBD

\begin{tabular}{|c|c|c|c|}
\hline Compound & $\operatorname{Pe}\left(10^{-6} \mathrm{~cm} / \mathrm{s}\right)$ & Known $\mathrm{Pe}\left(10^{-6} \mathrm{~cm} / \mathrm{s}\right)$ & Classification \\
\hline Theophylline & $0.08 \pm 0.01$ & $0.12 \sim 0.18$ & BBB- \\
\hline Verapamil & $23.82 \pm 1.82$ & $16 \sim 23$ & $\mathrm{BBB}+$ \\
\hline Testosterone & $34.08 \pm 4.78$ & 17 & $\mathrm{BBB}+$ \\
\hline BBD & $20.87 \pm 3.05$ & - & $\mathrm{BBB}+$ \\
\hline Sesamin & $0.00 \pm 0.01$ & - & BBB- \\
\hline
\end{tabular}

were incubated for $2 \mathrm{~h}$ with $5 \%(\mathrm{w} / \mathrm{v})$ dry skim milk in TBST buffer to block non-specific binding, then ERK, p38 JNK, AKT-1, COX-2, caspase-3, $\beta$-actin proteins for neuron cells were detected by a chemiluminescence detection system according to the manufacturer's instructions (ECL, Amersham, Berkshire, UK).

\section{Superoxide dismutase (SOD) assay}

Superoxide dismutase (SOD) activity was determined by a Superoxide Dismutase assay kit (Cayman, Ann Arbor, MI, USA). This method was based on the formation of red formazan from the reaction of 2- (4-iodophenyl) -3- (4-nitrophenol) -5 -phenyltetrazolium chloride and superoxide radical and assayed in a spectrophotometer at $505 \mathrm{~nm}$. The inhibition of the produced chromogen was proportional to the activity of the SOD present in the sample. A $50 \%$ inhibition was defined as one unit of SOD, and the specific activity was expressed as units per milligram protein.

\section{Lipid peroxidation}

Lipid peroxidation is quantified by measuring malondialdehyde (MDA) of PC12 cells and brain tissue of SD rats by lipid peroxidation (LPO) assay kit (Cayman). This kit works on the principle of condensation of one molecule of either MDA or 4-hydroxyalkenals with two molecules of $\mathrm{N}$-methyl-2-phenylindole to yield a stable chromophore. MDA levels were assayed by measuring the amount expressed in $5 \times 10^{5}$ cells of PC12 and SD brain tissue, and the absorbance at $500 \mathrm{~nm}$ was determined using a microplate reader (spectraMAX 340).

\section{Statistical analysis}

Data were expressed as the mean \pm SEM. In animal study, TTC data were analyzed by analysis of variance (ANOVA) with Student's $t$-tests. A $P$ value less than 0.05 was
(A)
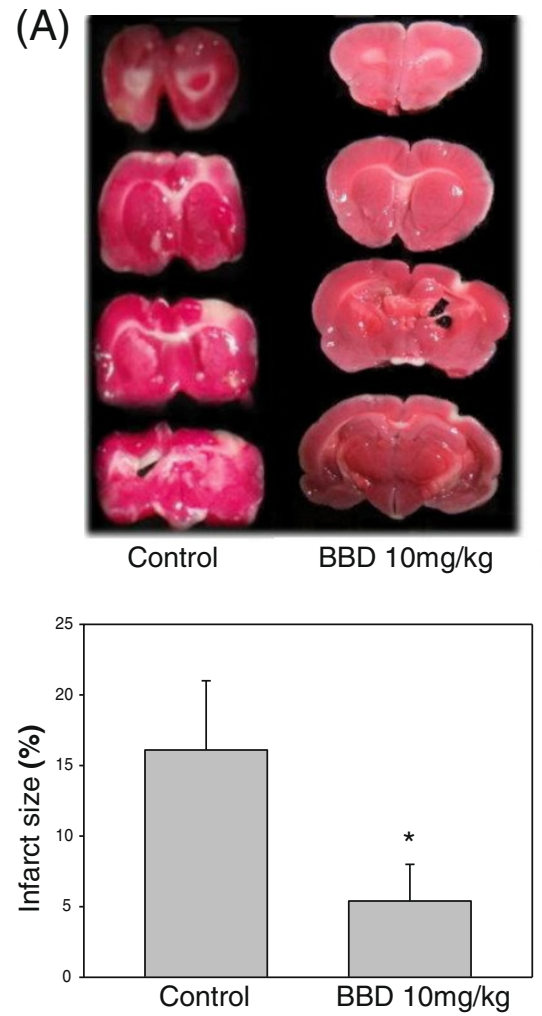

(B)

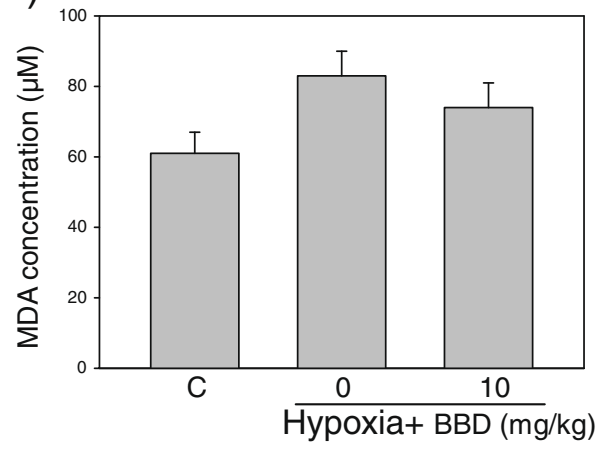

(C)

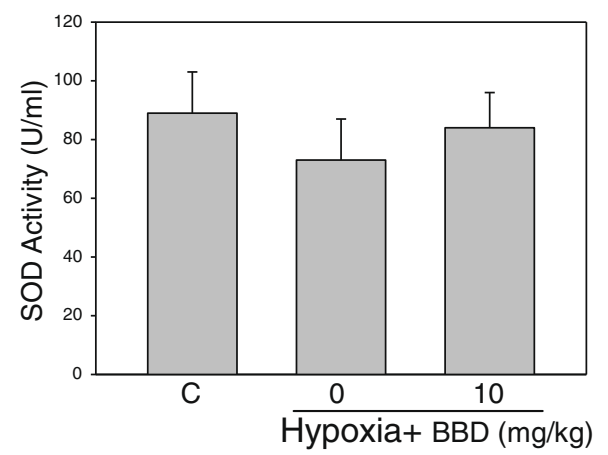

Figure 2 In vivo effect of BBD on the cerebral ischemia. SD rats treated with BBD i.p. 90 min after MACO had reduced infarct sizes of brains (A). Data are expressed as mean \pm SEM. ${ }^{*}: P<0.05$ as compared to the non-treated ischemic control. $(n=8)$. SOD activity and lipid peroxidation were determined by commercial assay kits (Cayman, Ann Arbor, MI, USA). Malondialdehyde (MDA) of SD rats was increased by ischemic stress but reduced by BBD (B) and SOD activity was restored by BBD (C). Data are expressed as mean \pm SEM. ${ }^{*}: P<0.05$ as compared to the hypoxia control. $(n=4)$ 


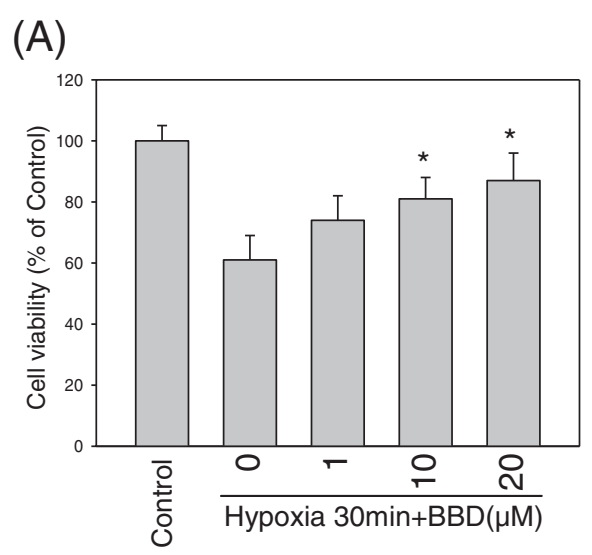

(C)

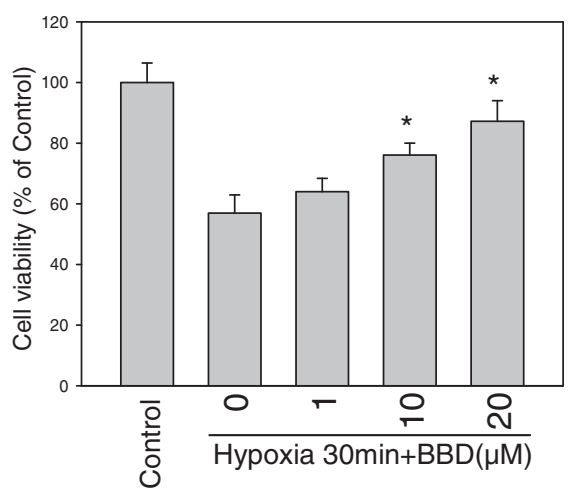

(B)

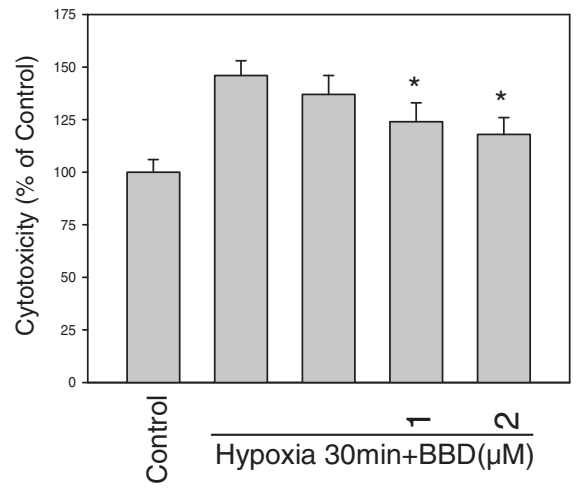

(D)

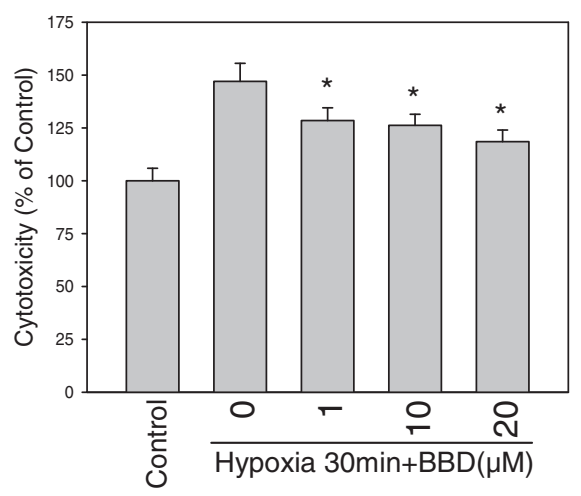

Figure 3 Effect of BBD on cell viability and cytotoxicity of PC12 and BV-2 cells under hypoxia. The cells were treated with hypoxia alone or in the presence of various concentrations $(1,10,20 \mu \mathrm{M})$ of BBD for 30 min. Cell viability of PC12 (A) and BV-2 cells (C) was increased and the $\mathrm{LDH}$ release, reduced $(\mathbf{B}, \mathbf{D})$ from hypoxia dose-dependently by BBD. Data are expressed as mean \pm SEM of three independent experiments in triplicate. ${ }^{*}: P<0.05$ as compared to the hypoxia control.

considered to be statistically significant. For In vitro study with single variable comparisons, Student's $t$-test was used. For multiple variable comparisons, data were analyzed by one-way ANOVA followed by Scheffe's test.

\section{Results}

In vivo effect of BBD on the cerebral ischemia

BBD had a high membrane permeability by PAMPA assay and was regard as a BBB permeable agent (Table 1). $\mathrm{SD}$ rats treated i.p. with $\mathrm{BBD}(10 \mathrm{mg} / \mathrm{kg}) 90 \mathrm{~min}$ after MCAO-induced ischemia reduced $66 \%$ of the infarct size as compared to the cerebral ischemia group (from 16.1 to $4.9 \%, P<0.05$; Figure 2A). MDA level of the BBD group was decreased $6 \%$ (from $83 \mu \mathrm{M}$ to $78 \mu \mathrm{M}$ ) as compared to the ischemia group (Figure 2B). BBD treatment increased a $24 \%$ SOD activity (from $68 \mu / \mathrm{mL}$ to $84 \mu / \mathrm{mL}$ ) as compared to the ischemia group (Figure 2C).

\section{Protection of hypoxic damage}

In order to investigate the protective mechanism of BBD, an in vitro hypoxia model was studied with neuronal celllines. Hypoxia can induce free radicals and damage neuronal cells, therefore the cell viability and LDH released from PC12 and BV-2 cells were measured using MTT and LDH ELISA assays. As shown in Figure 3A, the cell viability of PC12 cells under hypoxia for 30 min was preserved by the presence of BBD (1 to $20 \mu \mathrm{M})$. Hypoxia-induced LDH released was also decreased by BBD treatment $(P<0.05$, Figure $3 \mathrm{~B})$. Similarly, BV-2 cells were protected by BBD under hypoxia $(P<0.05$, Figure $3 \mathrm{C}, \mathrm{D})$.

\section{ROS scavenging effect of BBD}

Under hypoxia, ROS (as DCF signal) was increased nearly half (in PC12 cells) to four-fold (in BV-2 cells) as compared with their control cells. BBD protected cells against hypoxia-induced cell toxicity by decreasing the ROS accumulation in both cells (Figure 4A,B). The increase in MDA level was suppressed by BBD in hypoxia-exposed PC12 or BV-2 cells as compared with the control cells (Figure 4C,D, $P<0.05$ ).

\section{BBD inhibited IL-1, IL-6 and PGE 2}

$\mathrm{BBD}$ dose-dependently decreased the production of the inflammatory cytokine, IL-1 and IL-6 from BV-2 cells 

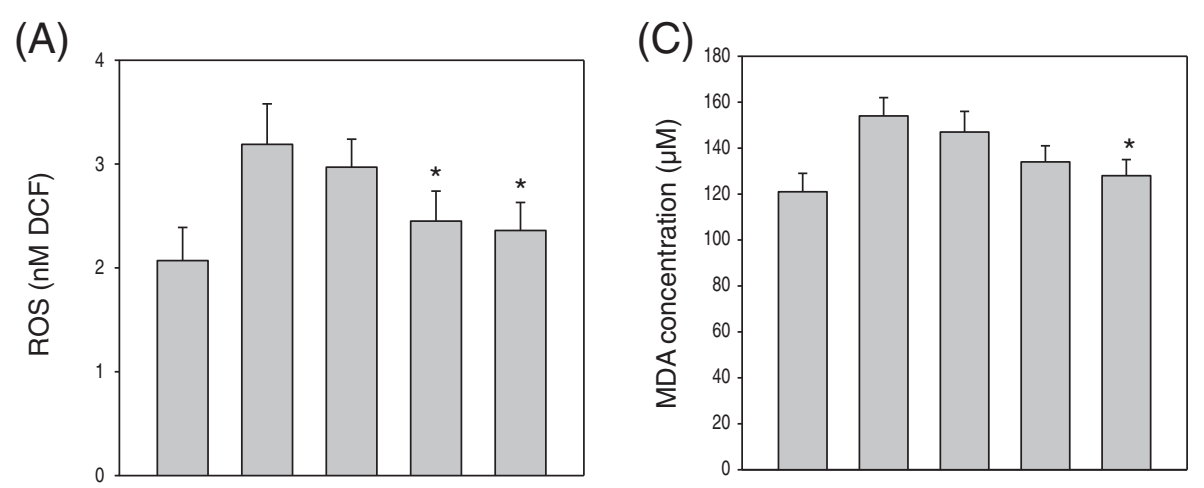

(B)

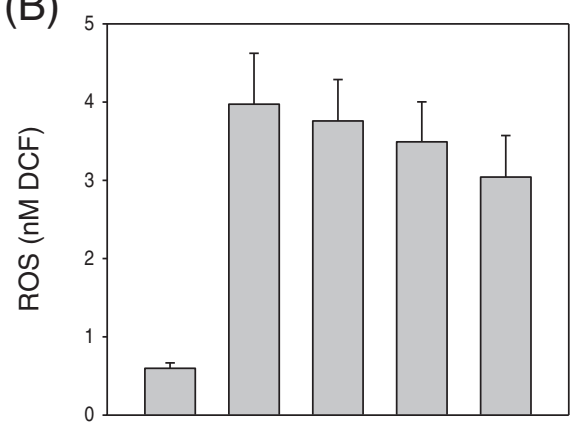

$(\mathrm{E})$

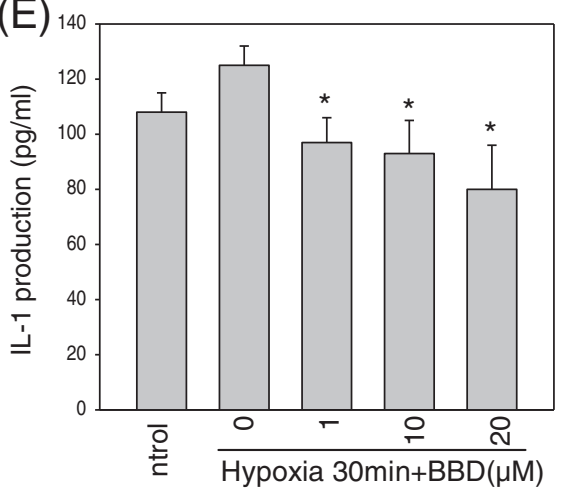

(G)

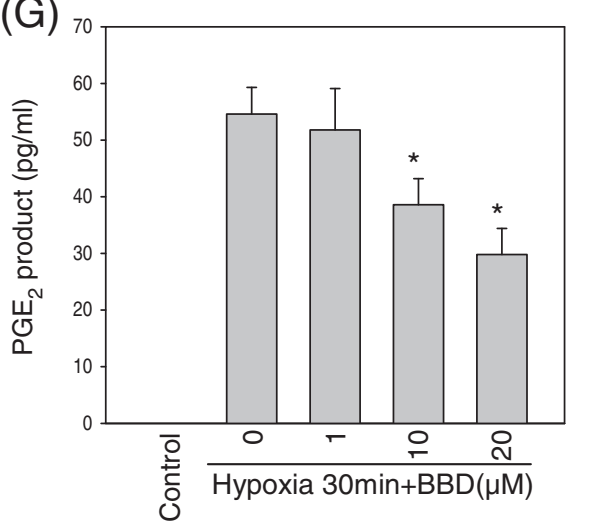

(D)

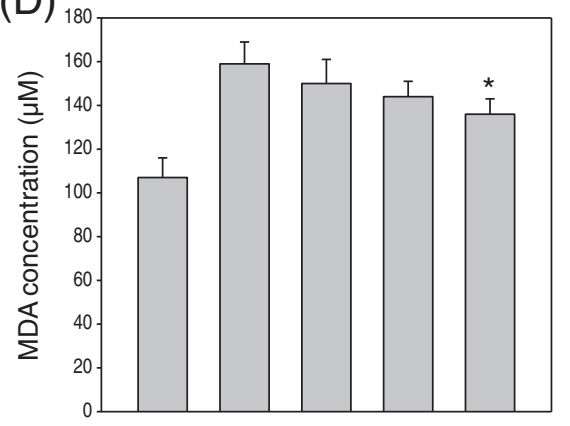

(F)

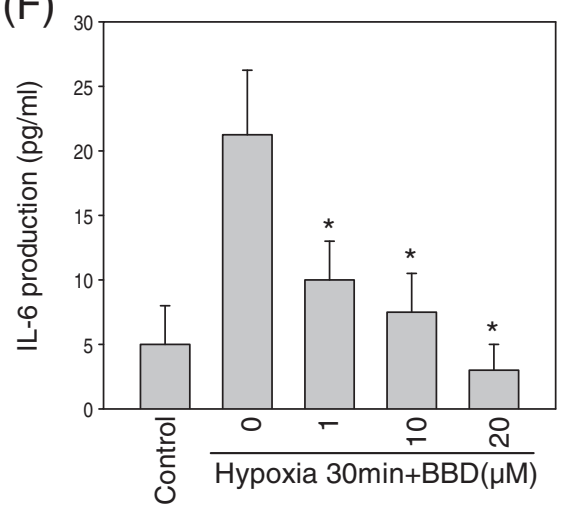

Figure 4 Effects of BBD on hypoxia-induced ROS generation, IL-1, IL-6 and PGE 2 productions. PC12 and BV-2 cells were treated with 1, 10, $20 \mathrm{\mu M}$ of BBD for 30 min. BBD reduced the generation of ROS under hypoxia in PC12 (A) and BV-2 (B) cells. MDA of PC12 (C) and BV-2 (D) cells were induced by 30-min hypoxia and reduced by BBD. BV-2 cells were treated with 1, 10, $20 \mu \mathrm{M}$ of BBD under hypoxia 30 min. BBD

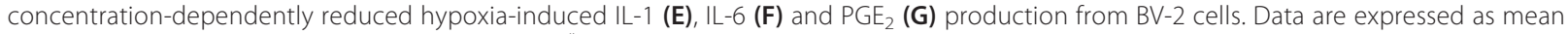
\pm SEM of 3 independent experiments in triplicate. ${ }^{*}: P<0.05$ as compared to the hypoxia control, $n=3$. 


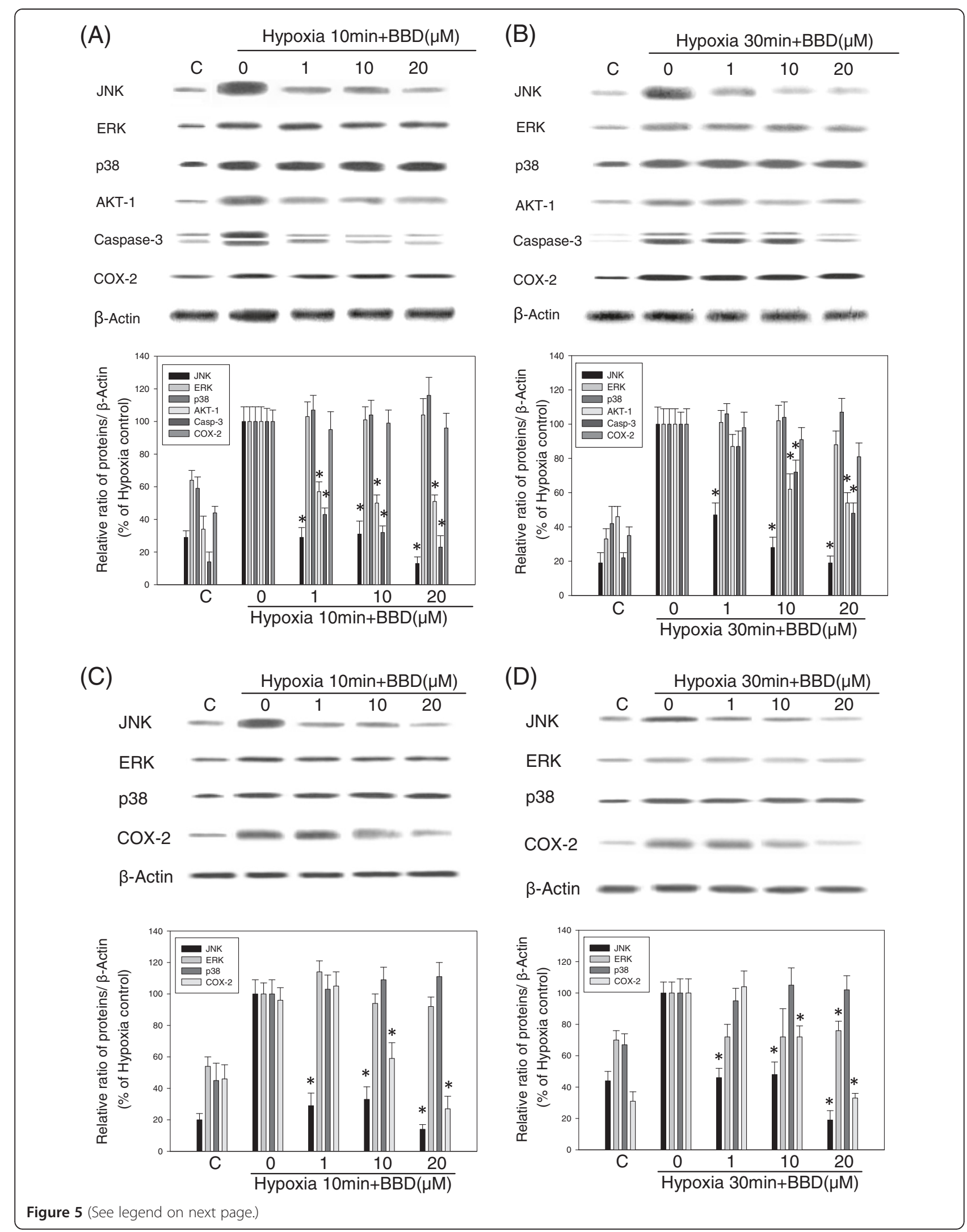


under hypoxia $(P<0.05$, Figure $4 \mathrm{E}, \mathrm{F})$. We further evaluated the effect of $\mathrm{BBD}$ on hypoxia-induced $\mathrm{PGE}_{2}$ production. BV-2 cells were incubated with 1, 10, $20 \mu \mathrm{M}$ of $\mathrm{BBD}$ then subjected to hypoxia for $30 \mathrm{~min}$. The results showed that BBD $(10$ and $20 \mu \mathrm{M})$ decreased $\mathrm{PGE}_{2}$ release from BV-2 cells significantly $(P<0.05$, Figure $4 G)$.

\section{BBD inhibited hypoxia-induced JNK MAPK, COX-2 and caspase-3 activation}

The effects of $\operatorname{BBD}(1,10,20 \mu \mathrm{M})$ on hypoxia-induced signaling pathways were further examined by Western blot assay (Figure 5). BBD $(20 \mu \mathrm{M})$ reduced expression of the following proteins: JNK (88 $\pm 6 \%)$, ERK (10 $\pm 7 \%)$, p38 $(-8 \pm 10 \%)$ MAPKs, AKT-1 (45 $\pm 6 \%)$, Caspase-3 (50 $\pm 7 \%)$, and COX-2 (13 $\pm 7 \%)$, respectively to the $10 \mathrm{~min}$ hypoxiainduced BV-2 cells $\left({ }^{*} \mathrm{P}<0.05\right.$; Figure $\left.5 \mathrm{~A}\right)$. This result is better than that of the 30 min hypoxia-induced BV-2 cells $\left({ }^{*} P<0.05\right.$; Figure 5B). Similarly, BBD $(20 \mu \mathrm{M})$ also suppressed hypoxia induced expression of the signaling proteins in PC12 cells: JNK ( $86 \pm 5 \%)$, ERK $(9 \pm 7 \%)$, p38 ( -10 $\pm 9 \%)$ MAPKs, and COX-2 $(75 \pm 11 \%)$, respectively $\left({ }^{*} \mathrm{P}<\right.$ 0.05 ; Figure $5 \mathrm{C}$ ). This was better than that of the $30 \mathrm{~min}$ hypoxia-induced PC12 cells ( ${ }^{*} \mathrm{P}<0.05$; Figure $\left.5 \mathrm{D}\right)$.

\section{Discussion}

The present study showed that BBD could pass the BBB by PAMPA assay and significantly protected animals from the focal cerebral ischemia. Furthermore, BBD was able to suppress MDA and preserve SOD activity in the ischemic rat brain. BBD at the concentrations of 10 to $20 \mu \mathrm{M}$, decreased hypoxia- induced cell viability, ROS generation and MDA levels in BV-2 and PC12 cells.

Excessive ROS production in the brain is believed to contribute to neurodegenerative processes [12,13]. Various dietary-derived antioxidants that inhibit the hypoxiainduced inflammation response may have neuroprotective potential $[14,15]$. Since sesamin and its related structure were reported to have protective effect on the hypoxiainduced inflammatory and oxidative stress [5,16], BBD, a sesamin derivative would have a similar effect. Effect of BBD on hypoxia-induced MDA stress might be through the activation of antioxidant signaling pathway such as Nrf2/ARE [17].

We found that 10 to 30 min hypoxia could significantly induce the activation of JNKs, AKT-1, and caspase-3 expression in BV-2 cells and JNK, ERK, COX-2 expression in. PC12 cells. Inhibition of JNK MAPK, COX-2 and caspase-3 can be expected to be beneficial in injuries involving microglia activation and inflammation. Specific inhibitors of JNK MAPK have been proven to reduce inflammation, slow down microglia activation and provide neuroprotective effects $[4,18,19]$. Studies have shown that antioxidant compounds inhibit JNK MAPK activation in microglia represent potential anti-inflammatory effects and protect neurons damage [5,20,21]. In addition, antioxidant compounds inhibit JNK MAPK activation in neuron and cardiomyocyte cells represent potential protective effects from hypoxic damage [5,22-24]. Sesamin can regulate microglial activities by inhibition of the intracerebral hemorrhage-induced p44/42 MAPK pathway and protect neuronal cells by inhibition of hypoxia-induced ERK, JNK, p38 MAPK [5,25]. BBD, a sesamin derivative also suppressed hypoxia-induced JNK MAPK expression in both cells significantly. Studies have shown that hypoxia induces MAPK activation and apoptosis factor Caspase-3 in vitro and in vivo [4,11]. Therefore, we evaluated the effect of BBD on hypoxia-induced signaling pathways including MAP kinases (JNK, ERK, p38), AKT-1, Caspase-3 and COX-2. Western blot analysis revealed that BBD (10 and $20 \mu \mathrm{M}$ ) significantly reduced JNK MAPK, AKT-1 and Caspase-3 expression in BV-2 cells as compared to hypoxia controls (Figure 5A,B). Similarly, BBD significantly reduced JNK MAPK and COX-2 expression in PC12 cells with both 10 and 30 min hypoxia as compared to hypoxia controls (Figure 5C,D). The results suggested that BBD restored the cell viability under hypoxic stress (Figure 3) through various pathways in each cells. This also agrees with a recent study that agent protects neuronal cells from $\mathrm{H}_{2} \mathrm{O}_{2}$-induced cell death, DNA fragmentation, and activation of caspase-3 and MAP kinase can ameliorate ischemic brain injury [26].

Induction of antioxidant enzymes has been considered as a promising strategy to combat with oxidative stress-related diseases. Previous studies shown that neuroprotective effects of antioxidants are due to increasing the level of antioxidant enzymes (e.g., SOD, catalase, G6PD), lowering of ROS, and preventing calcium release [5]. SOD is an important enzyme for eliminating free radicals and protect brain tissues from the ischemic injury [27]. Recently a study shows that sesamin and metabolites induce phase II antioxidant enzymes such as heme oxygenase-1 (HO-1) by activation of $\mathrm{Nrf} 2 / \mathrm{ARE}$ (antioxidant response element) signaling and suggesting their potential to reduce oxidative stress and ameliorate oxidative stress-related 
neurodegenerative diseases [17]. Since BBD was able to suppress MDA and preserve SOD activity in the ischemic rat brain and inhibited $40-50 \%$ of hypoxia-induced ROS, IL-1, and IL-6 production, it might also activate this antioxidant signaling pathway, and awaits future study.

ROS could induce cell damage by activating MAPK, and the nuclear transcription factor c-Jun [28]. The downstream of ROS signaling pathway could be associated with microglia activation. Since ROS are cytotoxic mediators in microglia [28]. BBD may also down-regulate hypoxia-induced inflammatory factor production via the inhibition of ROS generation which would reduce the activation of IL-1 and IL- 6 cytokines in BV-2 cells. The abilities of BBD to inhibit the hypoxia-induced COX-2 protein might be due to decreased attenuation of ROS signal, and reduced JNK MAPK in PC12 cells. Caspase-3 is an important apoptosis factor for neuronal cells [26]. Application of BBD $(100 \mu \mathrm{M})$ alone was not toxic to neurons (data not shown) and BBD at the lower concentration $(20 \mu \mathrm{M})$ inhibited the inflammation response in $\mathrm{BV}-2$ and $\mathrm{PC} 12$ cells under hypoxia. BBD significantly reduced infarct volume (about 66\%) of ischemic brain in SD rats as compared to the control group. Although the precise mechanism of BBD neuroprotection is not clear, the present in vitro and in vivo results suggest that its protection might be involved with the inhibition of release of ROS and inflammation during cerebral ischemia.

\section{Conclusion}

In conclusion, the present study shows that BBD with a high membrane permeability protected the brain after the focal cerebral ischemia. It also reduced lipid peroxidation and preserved superoxide dismutase activity from the ischemic brain. The protective mechanisms of BBD might be involved with the inhibition of JNK MAPK, COX-2, and caspase- 3 signal pathway. These results extend our knowledge of BBD to its therapeutic potential.

\section{Abbreviations \\ MTT: 3-(4,5-dimethyl-thiazol-2-yl)-2,5-diphenyl tetrazolium bromide; BBD: 3-bis (3-methoxybenzyl) butane-1,4-diol; JNK: c-Jun N-terminal kinase: COX: Cyclo-oxygenase; ERK: Extracellular signal-regulated kinase; p38 MAPK: p38 mitogen-activated protein kinase; PGE 2 : Prostaglandin E2; hypoxia: Oxygen/glucose deprivation; ROS: Reactive oxygen species; SOD: Superoxide dismutase.}

\section{Competing interests}

The authors declare that they have no competing interests.

\section{Authors' contributions}

C-WH participated in the design, infarction studies, data processing and manuscript preparation. Y-LC participated in animal procedures, SOD and MDA assay, and Western blot and in vitro assay. S-H Chuang participated in the PAMPA-BBB permeation assay. J-S Wang participated in the discussion. K-CJ prepared the final manuscript. All authors read, discussed and approved the final manuscript.

\section{Author details}

'Department of Biotechnology, Yuanpei University, Hsinchu 30015, Taiwan. ${ }^{2}$ Department of Small Molecule Drugs, Development Center for Biotechnology, New Taipei 22180, Taiwan. ${ }^{3}$ Department of Chinese Medicine, Tzuchi General Hospital, Taichung 42743, Taiwan. ${ }^{4}$ Department of Medical Research, Tungs' Taichung MetroHarbor Hospital, 699 Taiwan Boulevard, Sec.8, Taichung 43503, Taiwan.

Received: 22 November 2013 Accepted: 17 February 2014 Published: 18 February 2014

\section{References}

1. Ishida I, Kubo H, Suzuki S, Suzuki T, Akashi S, Inoue K, Maeda S, Kikuchi H, Sasaki H, Kondo T: Hypoxia diminishes toll-like receptor 4 expression through reactive oxygen species generated by mitochondria in endothelial cells. J Immunol 2002, 15:2069-2075.

2. Koga Y, Fujita M, Tsuruta R, Koda Y, Nakahara T, Yagi T, Aoki T, Kobayashi C, Izumi T, Kasaoka S, Yuasa M, Maekawa T: Urinary trypsin inhibitor suppresses excessive superoxide anion radical generation in blood, oxidative stress, early inflammation, and endothelial injury in forebrain ischemia/reperfusion rats. Neurol Res 2010, 32:925-932.

3. Tsuruta R, Fujita M, Ono T, Koda Y, Koga Y, Yamamoto T, Nanba M, Shitara M, Kasaoka S, Maruyama I, Yuasa M, Maekawa T: Hyperglycemia enhances excessive superoxide anion radical generation, oxidative stress, early inflammation, and endothelial injury in forebrain ischemia/reperfusion rats. Brain Res 2010, 1309:155-163.

4. Hou RCW, Wu CC, Yang CH, Jeng KC: Protective effects of sesamin and sesamolin on murine BV-2 microglia cell line under hypoxia. Neurosci Lett 2004, 367:10-13.

5. Hou RC, Huang HM, Tzen JT, Jeng KC: Protective effects of sesamin and sesamolin on hypoxic neuronal and PC12 cells. J Neurosci Res 2003, 74:123-133.

6. Khan MM, Ishrat T, Ahmad A, Hoda MN, Khan MB, Khuwaja G, Srivastava P, Raza SS, Islam F, Ahmad S: Sesamin attenuates behavioral, biochemical and histological alterations induced by reversible middle cerebral artery occlusion in the rats. Chem Biol Interact 2010, 183:255-263.

7. Di L, Kerns EH, Bezar IF, Petusky SL, Huang Y: Comparison of blood-brain barrier permeability assays: in situ brain perfusion, MDR1-MDCKII and PAMPA-BBB. J Pharm Sci 2009, 98:1980-1991.

8. Jeng KCG, Hou RCW: Sesamin and sesamolin: nature's therapeutic lignans. Curr Enzym Inhib 2005, 1:11-20.

9. Bush ML, Miyashiro JS, Ingram VM: Activation of a neurofilament kinase, a tau kinase, and a tau phosphatase by decreased ATP levels in nerve growth factor-differentiated PC-12 cells. Proc Natl Acad Sci USA 1995, 92:1861-1865.

10. Queiroga CS, Tomasi S, Widerøe M, Alves PM, Vercelli A, Vieira HL: Preconditioning triggered by carbon monoxide (CO) provides neuronal protection following perinatal hypoxia-ischemia. PLoS One 2012, 7:e42632.

11. Lu QR, Yuk D, Alberta JA, Zhu Z, Pawlitzky I, Chan J, McMahon AP, Stiles CD, Rowitch DH: Sonic hedgehog-regulated oligodendrocyte lineage genes encoding bHLH proteins in the mammalian central nervous system. Neuron 2000, 25:317-329

12. Chao CC, Hu S, Tsang M, Weatherbee J, Molitor TW, Anderson WR, Peterson PK: Effects of transforming growth factor-beta on murine astrocyte glutamine synthetase activity. Implications in neuronal injury. J Clin Invest 1992, 90:1786-1793.

13. Sun AY, Cheng JS: Neuroprotective effects of poly (ADP-ribose) polymerase inhibitors in transient focal cerebral ischemia of rats. Zhongguo Yao Li Xue Bao 1998, 19:104-108.

14. Hou RCW, Chen HL, Tzen JTC, Jeng KC: Effect of sesame antioxidants on LPS-induced NO production by BV2 microglial cells. Neuroreport 2003, 14:1815-1819.

15. Hou RCW, Chen YS, Chen CH, Chen YH, Jeng JC: Protective effect of 1,2,4-benzenetriol on LPS-induced NO production by BV2 microglial cells. J Biomed Sci 2006, 13:89-99.

16. Hamada N, Tanaka A, Fujita Y, Itoh T, Ono Y, Kitagawa Y, Tomimori N, Kiso Y, Akao Y, Nozawa Y, Ito M: Involvement of heme oxygenase-1 induction via Nrf2/ARE activation in protectionagainst $\mathrm{H} 2 \mathrm{O} 2$-induced $\mathrm{PC} 12$ cell death by a metabolite of sesamin contained in sesame seeds. Bioorg Med Chem 2011, 19:1959-1965. 
17. Barone FC, Irving EA, Ray AM, Lee JC, Kassis S, Kumar S, Badger AM, White RF, McVey MJ, Legos JJ, Erhardt JA, Nelson AH, Ohlstein EH, Hunter AJ, Ward K, Smith BR, Adams JL, Parsons AA: A second-generation p38 mitogen-activated protein kinase inhibitor, reduces brain injury and neurological deficits in cerebral focal ischemia. J Pharmacol Exp Ther 2001, 296:312-321.

18. Kaminska B, Gozdz A, Zawadzka M, Ellert-Miklaszewska A, Lipko M: MAPK signal transduction underlying brain inflammation and gliosis as therapeutic target. Anat Rec (Hoboken) 2009, 292:1902-1913.

19. Zeng KW, Fu H, Liu GX, Wang XM: Icariin attenuates lipopolysaccharideinduced microglial activation and resultant death of neurons by inhibiting TAK1/IKK/NF-kappaB and JNK/p38 MAPK pathways. Int Immunopharmacol 2010, 10:668-678.

20. Tabakman R, Jiang H, Levine RA, Kohen R, Lazarovici P: Apoptotic characteristics of cell death and the neuroprotective effect of homocarnosine on pheochromocytoma PC12 cells exposed to ischemia. J Neurosci Res 2004, 75:499-507.

21. Ha SK, Moon E, Kim SY: Chrysin suppresses LPS-stimulated proinflammatory responses by blocking NF-KB and JNK activations in microglia cells. NeurosCi Lett 2010, 485:143-147.

22. Liou SF, Hsu JH, Liang JC, Ke HJ, Chen IJ, Wu JR, Yeh JL: San-Huang-Xie-Xin-Tang protects cardiomyocytes against hypoxia/reoxygenation injury via inhibition of oxidative stress-induced apoptosis. J Nat Med 2012, 66:311-320.

23. Chiu PY, Chen N, Leong PK, Leung HY, Ko KM: Schisandrin B elicits a glutathione antioxidant response and protects against apoptosis via the redox-sensitive ERK/Nrf2 pathway in H9c2 cells. Mol Cell Biochem 2011, 350:237-250.

24. Jamarkattel-Pandit N, Pandit NR, Kim MY, Park SH, Kim KS, Choi H, Kim H, Bu $Y$ : Neuroprotective effect of defatted sesame seeds extract against in vitro and in vivo ischemicneuronal damage. Planta Med 2010, 76:20-26.

25. Fujimura N, Sumita S, Narimatsu E: Alteration in diaphragmatic contractility during septic peritonitis in rats: effect of polyethylene glycol-absorbed superoxide dismutase. Crit Care Med 2000, 28:2406-2414.

26. Shin MJ, Kim DW, Lee YP, Ahn EH, Jo HS, Kim DS, Kwon OS, Kang TC, Cho YJ, Park J, Eum WS, Choi SY: Tat-glyoxalase protein inhibits against ischemic neuronal cell damage and ameliorates ischemic injury. Free Radic Biol Med 2013, 67C:195-210

27. Katoh S, Mitsui Y, Kitani K, Suzuki T: Hyperoxia induces the neuronal differentiated phenotype of $\mathrm{PC} 12$ cells via a sustained activity of mitogen-activated protein kinase induced by Bcl-2. Biochem J 1999, 338:465-470.

28. Haddad JJ, Land SC: Redox/ROS regulation of lipopolysaccharide-induced mitogen-activated protein kinase (MAPK) activation and MAPK-mediated TNF-alpha biosynthesis. Br J Pharmacol 2002, 135:520-536.

doi:10.1186/1423-0127-21-15

Cite this article as: Hou et al:: Protective effect of a sesamin derivative, 3-bis (3-methoxybenzyl) butane-1, 4-diol onischemic and hypoxic neuronal injury. Journal of Biomedical Science 2014 21:15.

\section{Submit your next manuscript to BioMed Central and take full advantage of:}

- Convenient online submission

- Thorough peer review

- No space constraints or color figure charges

- Immediate publication on acceptance

- Inclusion in PubMed, CAS, Scopus and Google Scholar

- Research which is freely available for redistribution

Submit your manuscript at www.biomedcentral.com/submit
Ciomed Central 